\title{
Effect of Hormonal Contraceptives on the Total Antioxidants Status of Women from Isolo, Lagos State, Nigeria
}

\author{
Esther Ngozi Adejumo, Isaac Oluwole Adediji*, Abisola Oluwaseun Akinmulero \\ Department of Medical Laboratory Science, Babcock University, Ilishan Remo, Nigeria \\ Email: "adedijiisaac@gmail.com
}

Received 4 November 2015; accepted 23 January 2016; published 26 January 2016

Copyright @ 2016 by authors and Scientific Research Publishing Inc.

This work is licensed under the Creative Commons Attribution International License (CC BY). http://creativecommons.org/licenses/by/4.0/

(c) (i) Open Access

\begin{abstract}
The use of hormonal contraceptives has been implicated in the depletion of serum antioxidants and resultant promotion of oxidative stress which is associated with various disorders including cardiovascular disease and cancer. This study investigated serum total antioxidant status (TAS) in women taking hormonal contraceptives and compared their results with non-contraceptive users (age- and sex-matched). Sixty women aged 30 - 45 years, were enrolled for the study which included forty-five users of hormonal contraceptives from the Planned Parenthood Federation of Nigeria, Isolo, Lagos state and fifteen age-matched, apparently healthy, non-contraceptive users from the same geographical location were selected as controls. The in vitro determination of the serum total antioxidant status (TAS) was performed using Biorex enzymatic kit. Data obtained were statistically analyzed using student's t-test and $P<0.05$ was considered significant. The serum levels of TAS in the users of hormonal contraceptives were significantly lower than non-users $(P<0.05)$. The study concluded that women on hormonal contraceptives especially those taking either combined oral or combined injectable contraceptives were at risk of developing disorders associated with reduced levels of serum antioxidants.
\end{abstract}

\section{Keywords}

Hormonal Contraceptives, Oxidative Stress, Antioxidant Status

\section{Introduction}

Hormonal contraceptives are synthetic biochemical substances that act on the endocrine system and permit sex-

${ }^{*}$ Corresponding author.

How to cite this paper: Adejumo, E.N., Adediji, I.O. and Akinmulero, A.O. (2016) Effect of Hormonal Contraceptives on the Total Antioxidants Status of Women from Isolo, Lagos State, Nigeria. Journal of Biosciences and Medicines, 4, 107-111. http://dx.doi.org/10.4236/jbm.2016.41013 
ual union without resultant pregnancy.

Hormonal contraceptives are used by millions of women worldwide. Although other methods of contraception exist, the use of oral and injectable contraceptives is the most popular. In the United States, $18 \%$ of women who adopted contraceptive methods to prevent conception relied upon hormonal contraceptives [1].

There are two main classes of hormonal contraceptives and these include combined contraceptives which contain both an oestrogen and a progestin, most oral contraceptives fall under this category and progestogenonly contraceptives which contain only progesterone or a synthetic analogue (progestin).

In Africa, approximately $30 \%$ of women use birth control and more than this proportion would have used, if it were readily available. In Sub-Saharan Africa, the use of contraceptives among women, increased from about 5\% in 1991 to about 30\% in 2006 [2].

According to Nigeria Demographic and Health Survey (NHDS), the prevalence rate of hormonal contraceptives use among Nigerian women between the ages 15 - 49 was $13 \%$ in $2003,15 \%$ in 2008 and $18 \%$ in 2012. Further analysis of the total contraceptive rate in Nigeria revealed wide state variations, ranging from $0.3 \%$ in Jigawa to $41.6 \%$ in Lagos state as well as zonal variations ranging from $2.7 \%$ in the northwest to $28.5 \%$ in the southwest [3].

Recently, the possibility of alterations in various metabolic processes and antioxidant status, by hormonal contraceptives, has received much attention but unfortunately, there has been conflicting reports in this regard. Thibodeau et al. (2002) opined that this divergence in reports could be attributed to the chemical heterogeneity of the oestrogen family and their varying concentration [4].

Generally, stress can be described as inability to cope with increased demands. Oxidative stress occurs when an individual's antioxidant defense mechanism has been overwhelmed by destructive reactive oxygen species. Oxidative stress has been implicated in the pathogenesis of many diseases including cardiovascular disease, cancer, diabetes complications, macular degeneration and arthritis.

The antioxidant effect of oestrogen was observed in most of the in vivo studies performed on rats and women receiving hormone-replacement therapy [5]-[8]. The antioxidant activity of oestrogen has been attributed to prevention of expression and function of $\mathrm{NADP}^{+} / \mathrm{NADPH}$ oxidase, increase in the expression and activation level of endothelial isoform of the nitric oxide synthase (eNOS) and stimulation of the expression and activation of manganesse superoxide dismutase [9]-[11]. Contrarily, Bhat et al. (2003) and Gordon et al. (2005) reported the direct pro-oxidant effect of oestrogen in experimental model rats [12] [13]. Prokai-Tatrai et al. (2005) attributed the pro-oxidant effects of oestrogens to the metabolic conversion of oestrogens to catecholoestrogens by cytochrome p450. Catecholoestrogens are easily auto-oxidized to ortho-quinone by-products which are powerful oxidizing agents capable of generating reactive oxygen species [14].

Despite the divergent views about the relationship between the use of hormonal contraceptives in women and oxidative stress, there is paucity of information about this association in Nigeria. Lands et al. (2000) and Maxwell et al. (2006) recommended the study of total antioxidant status rather than monitoring the response to a single antioxidant, as this gives a representation of mixed antioxidant response [15] [16]. This study therefore aimed to determine the effect of hormonal contraceptives on the serum total antioxidants status of women who enrolled for the use of hormonal contraceptives at Planned Parenthood Federation of Nigeria, Isolo, Lagos State.

\section{Materials and Methods}

\subsection{Subjects}

A total of sixty eligible volunteers within the age range of 30 - 45 years were recruited for this study which included 45 women using hormonal contraceptives at the Planned Parenthood Federation of Nigeria, Isolo, Lagos State. These participants were divided into 18 subjects on combined oral contraceptives and 27 subjects on injectable contraceptives. 15 apparently healthy age and sex-matched subjects who had never used contraceptives were selected as controls. All the subjects were selected from the same geographical location. Exclusion criteria for participating in the study were; intake of antioxidant-vitamin supplements, smokers, alcohol users, those who have diabetes, cardiovascular diseases. The study was approved by Babcock University Ethical Committee.

\subsection{Sample Collection and Analysis}

Blood sample ( $5 \mathrm{ml}$ ) was aseptically collected by venipuncture from each subject using sterile disposable needles and syringes. The blood samples were dispensed into plain containers and were allowed to retract, to obtain sera 
for the determination of total antioxidant status. Biorex enzymatic kit was used for the in vitro colorimetric determination of serum total antioxidant status.

\subsection{Statistical Analysis}

Statistical analysis was done using the statistical package for social sciences (SPSS) version 17.0. Results were expressed in mean \pm s.d. Student's t-test was used to compare the means between the test and control subjects where $\mathrm{P}<0.05$ was considered significant.

\section{Results}

Comparison of the serum levels of Total antioxidant status (TAS) in hormonal contraceptive users and control subjects is presented in Table 1. There was a significant decrease in the serum levels of TAS of hormonal contraceptive users when compared with the control subjects.

Table 1. Comparison of the serum levels of total antioxidant status (TAS) in hormonal contraceptive users and control subjects.

\begin{tabular}{cccc}
\hline & $\begin{array}{c}\text { Hormonal contraceptives } \\
(\mathbf{n}=\mathbf{4 5})\end{array}$ & $\begin{array}{c}\text { Control subjects } \\
(\mathbf{n}=\mathbf{1 5})\end{array}$ & P-value \\
\hline $\begin{array}{c}\text { TAS (mmol/L) } \\
\text { mean } \pm \text { s.d }\end{array}$ & $1.0 \pm 0.60$ & $1.56 \pm 0.96$ & $0.000^{*}$ \\
\hline
\end{tabular}

*Significant at $\mathrm{P}<0.05$.

Table 2 shows the comparison of serum levels of TAS in both oral contraceptive users and control subjects. A significant decrease was observed in the serum levels of TAS of oral contraceptive users when compared with the control subjects.

Table 2. Comparison of serum levels of TAS in both oral contraceptive users and control subjects.

\begin{tabular}{cccc}
\hline & $\begin{array}{c}\text { Oral contraceptives } \\
(\mathbf{n}=\mathbf{1 8})\end{array}$ & $\begin{array}{c}\text { Control subjects } \\
(\mathbf{n}=\mathbf{1 5})\end{array}$ & P-value \\
\hline $\begin{array}{c}\text { TAS }(\mathbf{m m o l} / \mathbf{L}) \\
\text { mean } \pm \text { s.d }\end{array}$ & $1.17 \pm 0.74$ & $1.56 \pm 0.96$ & $0.020^{*}$ \\
\hline
\end{tabular}

*Significant at $\mathrm{P}<0.05$.

Comparison of serum TAS for both injectable users and control subjects is shown in Table 3 . There was a significant decrease in the serum TAS of injectable contraceptive users when compared with the control subjects.

Table 3. Comparison of serum levels of TAS in both oral contraceptive users and control subjects.

\begin{tabular}{|c|c|c|c|}
\hline & $\begin{array}{l}\text { Injectable contraceptives } \\
\qquad(\mathrm{n}=27)\end{array}$ & $\begin{array}{l}\text { Control subjects } \\
\quad(\mathbf{n}=15)\end{array}$ & P-value \\
\hline $\begin{array}{c}\text { TAS }(m m o l / L) \\
\text { mean } \pm \text { s.d }\end{array}$ & $0.94 \pm 0.64$ & $1.56 \pm 0.96$ & $0.000^{*}$ \\
\hline
\end{tabular}

*Significant at $\mathrm{P}<0.05$.

\section{Discussion}

The results of the present study revealed that there was significantly lower levels of serum TAS in users of both oral and injectable hormonal contraceptives when compared with non-contraceptive users. This is in agreement with the study of Palan et al. (2010) who reported that hormonal contraceptives deplete antioxidant vitamins and trace elements, as measured by the activity of coenzyme $\mathrm{Q}_{10}$, vitamin $\mathrm{E}$ and total antioxidant activity [17]. Akinloye et al., 2011 attributed decrease in the serum levels of antioxidant trace elements more specifically to increased use of oral contraceptives [18].

Some other studies however, have reported the antioxidant function of oestrogen which may exert protective 
effect on the cardiovascular system [19] [20]. Thibodeau et al. (2002) and Pincemail et al. (2007) attributed these conflicting reports to the heterogeneity of the synthetic hormonal contents of these contraceptives [4] [21].

According to Wassman et al. (2005), the antioxidant effects of oestrogens are antagonized by progestins via the activation of NADPH oxidase and the inhibition of the expression and activity of manganese superoxide dismutase (MnSOD) and extracellular SOD [22]. Therefore it implies that the counteractive effect of progestin would result into decrease in the serum total antioxidant status especially in women taking either combined oral or combined injectable contraceptives, as revealed by the findings of the present study.

\section{Conclusion}

The findings of this study revealed a significant decrease in the serum levels of total antioxidant status among hormonal contraceptive users. This suggests that women taking hormonal contraceptives are at high risk of oxidative stress related diseases. Though alterations in various metabolic processes and antioxidant status associated with the use of hormonal contraceptives remain controversial, prospective large scale studies need to be performed in Nigeria to further elucidate this association.

\section{References}

[1] Mosher, W.D. and Jones, J. (2010) Use of Contraception in the United States. Vital and Health Statistics, 23, 1982-2008.

[2] Cleland, J.G., Ndugwa, R.P. and Zulu, E.M. (2011) Family Planning in Sub-Saharan Africa: Progress or Stagnation? Bulletin of the World Health Organization, 89, 137-143. http://dx.doi.org/10.2471/BLT.10.077925

[3] Nigeria (2013) Demographic Health Survey; Key Findings. 67-69, 72-74.

[4] Thibodeau, P.A., Kachadourian, R., Lemay, R., Bisson, M., Day, B.J. and Paquette, B. (2002) In Vitro Pro- and Antioxidant Properties of Estrogens. Journal of Steroid Biochemistry and Molecular Biology, 81, 227-236. http://dx.doi.org/10.1016/S0960-0760(02)00067-5

[5] Dantas, A.P., Tostes, R.C.A., Fortes, Z.B., Costa, S.G., Nigro, D. and Carvalho, M.H. (2002) In Vivo Evidence for Antioxidant Potential of Estrogen in Microvessels of Female Spontaneously Hypertensive Rats. Hypertension, 39, 405411. http://dx.doi.org/10.1161/hy0202.102993

[6] Wakatsuki, A., Okatani, Y., Ikenoue, N., Shinohara, K., Watanabe, K. and Fukaya, T. (2003) Effect of Lower Dose of Oral Conjugated Equine Estrogen on Size and Oxidative Susceptibility of Low-Density Lipoprotein Particles in Postmenopausal Women. Circulation, 108, 808-813. http://dx.doi.org/10.1161/01.CIR.0000084552.54277.64

[7] Ahotupa, M., Rauramo, I., Vasankari, T.J., Skouby, S.O. and Hakonen, T. (2004) Estrogen Replacement Therapy in Combination with Continuous Intrauterine Progestin Administration Reduces the Amount of Circulating Oxidized LDL in Postmenopausal Women: Dependence on the Dose of Progestin. Annals of Medicine, 36, 278-284. http://dx.doi.org/10.1080/07853890410032820

[8] Misra, R., Mangi, S., Joshi, S., Mittal, S., Gupta, S.K. and Pandey, R.M. (2006) LycoRed as an Alternative to Hormone Replacement Therapy in Lowering Serum Lipids and Oxidative Stress Markers: A Randomized Controlled Clinical Trial. Journal of Obstetrics and Gynaecology Research, 32, 299-304. http://dx.doi.org/10.1111/j.1447-0756.2006.00410.x

[9] Wagner, K.H., Kamal-Eldin, A. and Elmadfa, I. (2004) Gamma-Tocopherol—An Underestimated Vitamin? Annals of Nutrition and Metabolism, 48, 169-188. http://dx.doi.org/10.1159/000079555

[10] Chambaliss, K.L. and Shaul, P.W. (2002) Estrogen Modulation of Endothelial Nitric Oxide Synthase. Endocrine Reviews, 23, 665-686. http://dx.doi.org/10.1210/er.2001-0045

[11] Strehlow, K., Rotter, S. and Wassmann, S. (2003) Modulation of Antioxidant Enzyme Expression and Function by Estrogen. Circulation Research, 93, 170-177. http://dx.doi.org/10.1161/01.RES.0000082334.17947.11

[12] Bhat, H.K., Calaf, G., Hei, T.K., Loya, T. and Vadgama, J.V. (2003) Critical Role of Oxidative Stress in Estrogen-Induced Carcinogenesis. Proceedings of the National Academy of Sciences of the United States of America, 100, 3913-3918. http://dx.doi.org/10.1073/pnas.0437929100

[13] Gordon, K.B., Macrae, I.M. and Carswell, H.V. (2005) Effects of $17 \beta$-Estradiol on Cerebral Ischaemic Damage and Lipid Peroxidation. Brain Research, 1036, 155-162. http://dx.doi.org/10.1016/j.brainres.2004.12.052

[14] Prokai-Tatrai, K. and Prokai, L. (2005) Impact of Metabolism on the Safety of Estrogen Therapy. Annals of the New York Academy of Sciences, 1052, 243-257. http://dx.doi.org/10.1196/annals.1347.018

[15] Lands, L.C., Grey, V.L. and Grenier, C. (2000) Total Plasma Antioxidant Capacity in Cystic Fibrosis. Paediatric Pulmonology, 29, 81-87. http://dx.doi.org/10.1002/(SICI)1099-0496(200002)29:2<81::AID-PPUL1>3.0.CO;2-N 
[16] Maxwell, S.R., Dietrich, T. and Chapple, I.L. (2006) Prediction of Serum Total Antioxidant Activity from the Concentration of Individual Serum Antioxidants. Clinica Chemica Acta, 372, 188-194. http://dx.doi.org/10.1016/j.cca.2006.04.015

[17] Palan, P.R., Strube, F. and Mikhail, M.S. (2010) Effects of Oral, Vaginal and Transdermal Hormonal Contraception on Serum Levels of Coenzyme Q10, Vitamin E and Total Antioxidant Activity. Obstetrics and Gynecology International, 2010, Article ID: 925635. http://dx.doi.org/10.1155/2010/925635

[18] Akinloye, O., Adebayo, T.O., Oguntibeju, O.O., Oparinde, D.P. and Ogunyemi, E.O. (2011) Effects of Contraceptives on Serum Trace Elements, Calcium and Phosphorus Levels. West Indian Medical Journal, 60, 308-315.

[19] Brown, L., Hoong, I. and Doggrell, S.A. (2000) The Heart as a Target for Oestrogens. Heart, Lung and Circulation, 9, 113-125. http://dx.doi.org/10.1046/j.1444-2892.2000.009003113.x

[20] Ling, S., Komesaroff, P. and Sudhir, K. (2006) Cellular Mechanisms Underlying the Cardiovascular Actions of Estrogens. Clinical Science, 111, 107-118. http://dx.doi.org/10.1042/CS20050084

[21] Pincemail, J., Vanbelle, S., Gaspard, U., Collette, G., Haleng, J. and Cheramy-Bien, J.P. (2007) Effect of Different Contraceptive Methods on the Oxidative Stress Status in Women Aged 40-48 Years from the ELAN Study in the Province of Liege, Belgium. Human Reproduction, 22, 2335-2343. http://dx.doi.org/10.1093/humrep/dem146

[22] Wassmann, K., Wassmann, S. and Nickenig, G. (2005) Progesterone Antagonizes the Vasoprotective Effect of Estrogen on Antioxidant Enzyme Expression and Function. Circulation Research, 97, 1046-1054. http://dx.doi.org/10.1161/01.RES.0000188212.57180.55 